\title{
Ethische Normen des frühen Christentums
}

\author{
Gut - Leben - Leib - Tugend. Kontexte und Normen neutestamentlicher Ethik / \\ Contexts and Norms of New Testament Ethics. Band IV \\ Hrsg. v. Friedrich W. Horn, Ulrich Volp u. Ruben Zimmermann, in Zus.-Arb. m. \\ Esther Verwold
}

Ethische Normen des frühen Christentums

Herausgegeben von FRIEDRICH W. HORN, ULRICH VOLP und RUBEN ZIMMERMANN

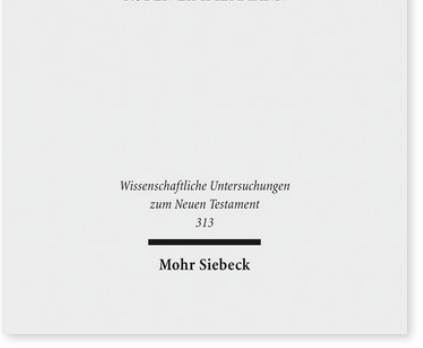

2013. XII, 478 Seiten. WUNT I 313

SBN 978-3-16-152500-1 DOI 10.1628/978-3-16-152500-1 eBook PDF 159,00€

ISBN 978-3-16-152499-8

Leinen $159,00 €$
Gutes und Güter, Leben, Leib, Tugend - in diesem Band werden die Vorträge der ersten vier Symposien der Mainz Moral Meetings aus den Jahren 2009-2011 zu diesen Themen zusammengefasst. Ein interdisziplinärer Zugang durch Bibelwissenschaft, Judaistik, Altphilologie, Philosophie, Patristik, Systematische Theologie und weitere Disziplinen eröffnet einen Blick auf die ethischen Normen des frühen Christentums. Die Autoren der Beiträge fragen nach den Möglichkeiten von Norm und Normbegründung einer frühchristlichen Ethik in ausgewählten Bereichen sowohl im Kontext antiker Philosophie als auch in gegenwärtiger Verantwortung.

Inhaltsübersicht

Hinführung - Grundlagen

Ruben Zimmermann: Pluralistische Ethikbegründung und Normenanalyse im Horizont einer »impliziten Ethik« frühchristlicher Schriften - Gerd Theißen: Bibelhermeneutik und Ethikbegründung. Wie können Imperative in religiösen Erfahrungen begründet werden?

I. »Gut"/das »Gute« als ethische Norm in Antike und Christentum

Ruben Zimmermann: Das »Gute« als ethische Norm in Antike und Christentum. Gut, Güter, Güterabwägung in philosophischen und christlichen Ethiken - Jan G. van der Watt: Reflections on doing what is good and true in the Gospel of

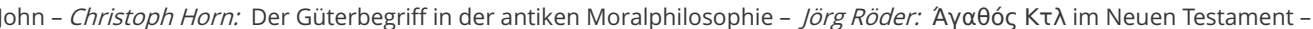
eine historisch-semantische Annäherung - Ruben Zimmermann: Güterabwägung als Verfahren einer frühchristlichen Ethik? Zur Begründung von Normen am Beispiel des 1. Korintherbriefs - Notger Slenczka: Was heißt »gut«? Plädoyer für eine deskriptive christliche Ethik im Anschluss an Friedrich Schleiermacher und Max Scheler

II. »Leben« als ethische Norm in Antike und Christentum

Ruben Zimmermann: "Leben« als ethische Norm in Antike und Christentum. Begriff und Funktion des Lebens im ethischen Diskurs - Nikolaus Schneider: Wie viel Naturwissenschaft verträgt die Theologie? - Maren Niehoff: Halacha, Nomos oder Tugend im hellenistischen Judentum - Manfred Lang: Lebenskunst und Kohärenz. Beobachtungen anhand von Epiktet und dem Römerbrief - Eckart David Schmidt: Kult und Ethik: Leben »heiliger « Gemeinden. Der Heiligkeitsbegriff in ethischen Begründungszusammenhängen im 1. Petrusbrief - Mira Stare: Der Lebensbegriff als ethische Norm im Johannesevangelium - Werner Zager: Zwischen Schopenhauer und Nietzsche. Albert Schweitzers Lebensethik

III. »Leib« als ethische Norm in Antike und Christentum

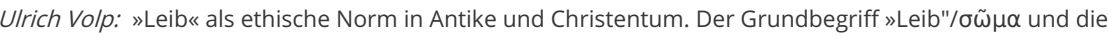
Begründungszusammenhänge antiker christlicher Ethik - Jochen Althoff: Die Rolle des Körpers und seiner Bedürfnisse in de aristotelischen Ethik - Lorenzo Scornaienchi: Die Unterscheidung von $\sigma \alpha ́ \rho \xi$ und $\sigma \omega \tilde{\mu} \alpha$ und ihre Konsequenzen für die Ethik des Paulus - David Horrell: $\sigma \tilde{\omega} \mu \alpha$ as a Basis for Ethics in Paul - Sebastian Moll: Marcions trotzige Ethik - Frederick D. Aquino: Maximus on the Beginning and End of Rational Creatures

IV. »Tugend« als ethische Norm in Antike und Christentum

Friedrich W. Horn: »Tugend « als ethische Norm in Antike und Christentum. Tugend und Tugendbegriff in griechischhellenistischer Philosophie, biblischer, jüdischer und frühchristlicher Theologie - Wilhelm Blümer: Schicksalswille und Willensfreiheit im 8. Jahrhundert vor Christus. Die Verpflichtung auf ein tugendhaftes Leben bei Hesiod - Maximilian Forschner: Mens perfecta. Bemerkungen zum stoischen Tugendbegriff - Friedrich W. Horn: Tugendlehre im Neuen Testament? Eine Problemanzeige - Christian Hengstermann: Leben des Einen - Der Tugendbegriff des Origenes - Ulrich Volp Der Tugendbegriff des Origenes - eine Erwiderung auf Christian Hengstermann

Friedrich Wilhelm Horn Geboren 1953; 1972-78 Studium der Ev. Theologie in Wuppertal und Göttingen; 1982 Promotion; 1990 Habilitation; seit 1996 Professor für Neues Testament an der Johannes Gutenberg-Universität Mainz.

Ulrich Volp Geboren 1971; Studium in Marburg, Heidelberg, St. Andrews und Cambridge/UK; 2001 Promotion und 2006 Habilitation in Bonn; seit 2008 Universitätsprofessor für Kirchen- und Dogmengeschichte (Schwerpunkt Alte Kirche) an der Evangelisch-Theologischen Fakultät der Johannes Gutenberg-Universität Mainz. https://orcid.org/0000-0003-2510-0879

Ruben Zimmermann Born 1968; 1999 Dr. theol. from the University of Heidelberg; 2003 Habilitation from the LudwigMaximilians-University München; currently Professor of New Testament and Ethics at the Johannes Gutenberg-University in Mainz, Germany and research associate at the Department of Old and New Testament Studies of the University of the Free State, Bloemfontein, South Africa.

Mohr Siebeck GmbH \& Co. KG

Postfach 2040

D-72010 Tübingen

info@mohrsiebeck.com

www.mohrsiebeck.com 
https://orcid.org/0000-0002-1620-4396

Esther Verwold Geboren 1982; seit 2010 Doktorandin am Seminar für Kirchengeschichte an der Johannes GutenbergUniversität Mainz.

Jetzt bestellen:

https://mohrsiebeck.com/buch/ethische-normen-des-fruehen-christentums-9783161525001?no_cache=1 order@mohrsiebeck.com

Telefon: +49 (0)7071-923-17

Telefax: +49 (0)7071-51104 